ISSN 0258-7122

Bangladesh J. Agril. Res. 38(1): 11-18, March 2013

\title{
GENETIC DIVERSITY ANALYSIS IN Brassica rapa USING MORPHOLOGICAL CHARACTERS
}

\author{
N. JAHAN ${ }^{1}$, S. R. BHUIYAN ${ }^{2}$, M. Z. A.TALUKDER ${ }^{3}$ \\ M. A. ALAM ${ }^{4}$ AND M. PARVIN ${ }^{5}$
}

\begin{abstract}
A field experiment was conducted in the experimental field of Genetics and Plant Breeding Department, Sher-e Bangla Agricultural University, Dhaka, Bangladesh to study on genetic diversity in $10 \mathrm{~F}_{4}$ lines obtained through intervarietal crosses along with 8 released varieties of Brassica rapa during November 2007 to February 2008. Different Multivariate analyses were performed to classify 18 genotypes. All the genotypes were grouped into four clusters. Cluster IV was the largest comprising of 7 genotypes and cluster II was the smallest with 2 genotypes. Cluster II had the highest intra-cluster distance and Cluster I had the lowest intra cluster distance. Inter cluster distance was maximum (11.697) between clusters II and III. The results revealed that genotypes chosen for hybridization from clusters with highest distances would give high heterotic $F_{1}$ and broad spectrum of variability in segregating generations. The characters- number of primary branches/plant, number of secondary branches/plant and days to 50\% flowering contributed maximum towards divergence among Brassica genotypes. Considering cluster distance, inter genotypic distance and other agronomic performance G2 and G14 from cluster I; G18 from cluster II; G1, G9 and G12 from cluster III and G16 and G17 from cluster IV may be considered as better parents for future uses in hybridization program.
\end{abstract}

Keywords: Brassica rapa, morphological characters and genetic diversity.

\section{Introduction}

The Oleiferous Brassica symbolized by rapeseed and mustard is one of the leading oilseed crops in our country. Brassica is an important genus of plant kingdom consisting of over 3200 species with highly diverse morphology. In Bangladesh, more than 134.875 thousand metric tons of local rape and mustard produced from total 392.900 thousand acres of cultivable land and about 540.005 thousand metric tons of rape and mustard produced from total 127.145 thousand acres of cultivable land in the year 2006-2007 (BBS, 2008). It is used as a condiment, salad, green manure and fodder crop and as a leaf and stem vegetable in the various mustard growing countries of the world. It is mainly self-

${ }^{1}$ Scientific Officer, Plant Breeding Division, RARS, Rahmatpur, Barisal, ${ }^{2}$ Professor, Department of Genetics and Plant Breeding, Sher-e-Bangla Agricultural University (SAU), Dhaka, ${ }^{3}$ Scientific Officer, Plant Breeding Division, BARI, Gazipur, ${ }^{4}$ Scientific Officer, RARS, Ishurdi, ${ }^{5}$ Department of Genetics and Plant Breeding, SAU, Bangladesh. 
pollinating crop, although on an average, 7.5 to $30 \%$ out-crossing does occur under natural field conditions (Abraham, 1994; Rakow and Woods, 1987).

Genetic diversity arises either due to geographical separation or due to genetic barriers to crossability. Genetic diversity plays an important role in plant breeding because hybrids between lines of diverse origin generally display a great heterosis than those between closely related strains (Singh, 1983) which permits to select the genetically divergent parents to obtain the desirable recombination in the segregating generations. Precise information about the extent of genetic divergence and on characters used for discrimination among the population is crucial in any crop improvement programme, because selection of parents based on genetic divergence has become successful in several crops (Ashana and Pandey, 1980; Ananda and Rawat, 1984; De et al., 1988). The present study was, therefore, undertaken to analyze the genetic divergence of 18 genotypes.

\section{Materials and Method}

A field experiment was conducted in the experimental field of Genetics and Plant Breeding Field Laboratory of Sher-e Bangla Agricultural University (SAU), Dhaka, Bangladesh during the period from November 2007 to March 2008. Eighteen genotypes were used in the study (Table 1). The seeds of 18 genotypes were collected from Brassica Breeding Project of SAU, Dhaka-1207, Bangladesh. The seeds of parents and $F_{4}$ materials were grown following Randomized Complete Block Design (RCBD) with three replications. The size of the plot was $5 \mathrm{~m} \times 25 \mathrm{~m}$. Seeds were sown in lines in the experimental plots on $11^{\text {th }}$ November 2007 by hand uniformly. Manure and fertilizer were applied @ $250 \mathrm{~kg}$ urea, $170 \mathrm{~kg}$ TSP, $85 \mathrm{~kg}$ MP, $150 \mathrm{~kg}$ gypsum, and $60 \mathrm{~kg}$ borax per hectare. The entire amount of TSP, MP, gypsum, and borax were applied during the final preparation of land. Urea was applied in two equal installments before sowing and flowering. Thinning and gap filling, weeding and mulching, irrigation, other intercultural operations and plant protection measures, etc. were done as and when needed. Data were recorded on selected characters viz., plant height $(\mathrm{cm})$, no. of primary branches/plant, no. of secondary branches/plant, days to $50 \%$ flowering, days to maturity, siliquae/plant, siliqua length, seeds/pod, 1000 -seed weight and yield/plant from randomly selected plant. Genetic diversity was worked out following Mahalanobis's (1936) generalized distance $\left(D^{2}\right)$ extended by Rao (1952). Clustering of genotypes was done according to Tocher's method (Rao, 1952). All the statistical analyses were done using GENSTAT5 programme. 
Table 1. Sources of 18 Brassica rapa genotypes.

\begin{tabular}{|c|c|c|}
\hline Designation & Genotypes & Sources \\
\hline G1 & BARI Sarisha-6 & BARI \\
\hline G2 & SS-75 & BARI \\
\hline G3 & $\mathrm{F}_{6}$ & SAU \\
\hline G4 & Tori-7 & BARI \\
\hline G5 & BARI Sarisha-9 & BARI \\
\hline G6 & $\mathrm{F}_{6} \times$ BARI Sarisha- 9 & SAU \\
\hline G7 & BARI Sarisha- $9 \times F_{6}$ & SAU \\
\hline G8 & Tori-7×BARI Sarisha-6 & SAU \\
\hline G9 & BARI Sarisha-6×Tori-7 & SAU \\
\hline G10 & Tori- $7 \times \mathrm{F}_{6}$ & SAU \\
\hline G11 & $\mathrm{F}_{6} \times$ Tori-7 & SAU \\
\hline G12 & Tori-7×SS-75 & SAU \\
\hline G13 & SS-75 $\times$ Tori-7 & SAU \\
\hline G14 & BARI sarisha-9×BARI Sarisha-6 & SAU \\
\hline G15 & BARI sarisha-6×BARI Sarisha-9 & SAU \\
\hline G16 & BARI Sarisha-15 & BARI \\
\hline G17 & Real Tori-7 & Farmer's field \\
\hline G18 & SAU Sarisha-1 & SAU \\
\hline
\end{tabular}

\section{Results and Discussion}

The analysis of variance showed significant variations among all the genotypes for all the ten characters studied. A two-dimensional scatter diagram was constructed using component I in X-axis and component II in Y-axis reflecting in the relative position (Fig. 1). As per scatter diagram, the genotypes were apparently distributed into four clusters. It was also revealed that the genotypes of cluster II was more diverse from the genotypes of cluster I. 


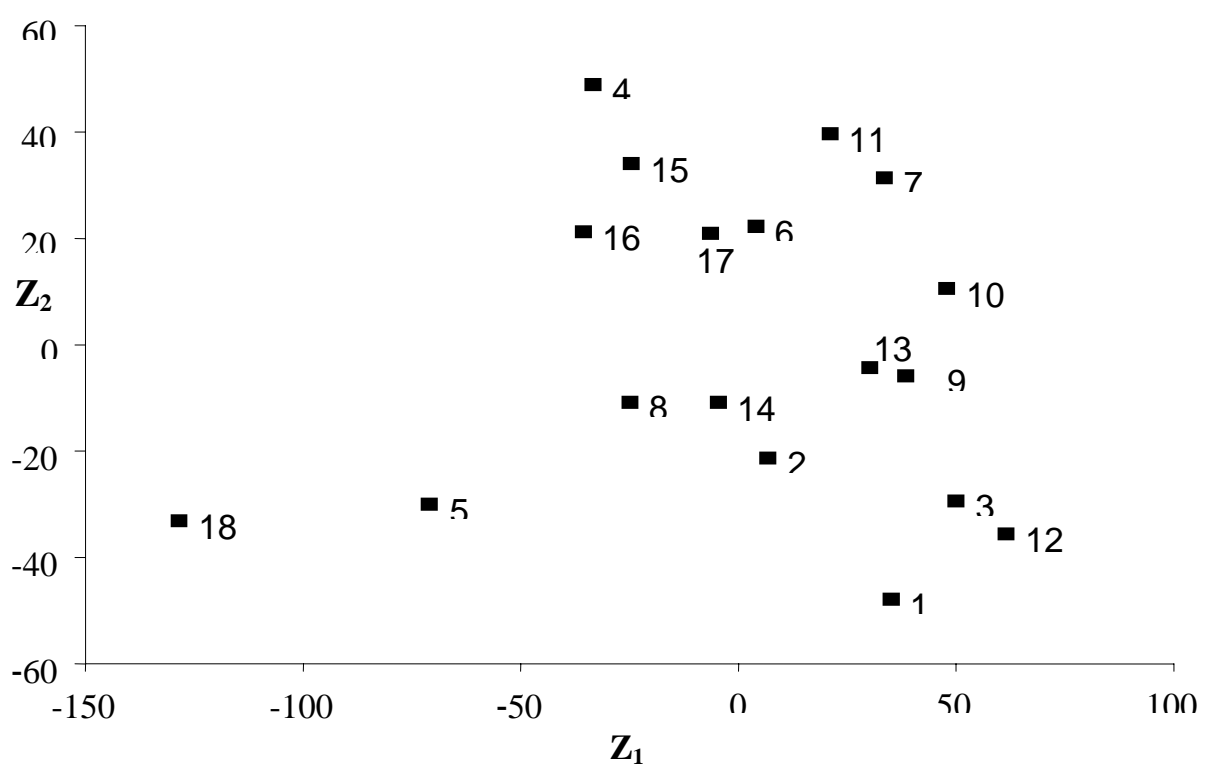

Fig. 1. Scatter distribution of 18 Brassica rapa genotypes based on their principal component scores.

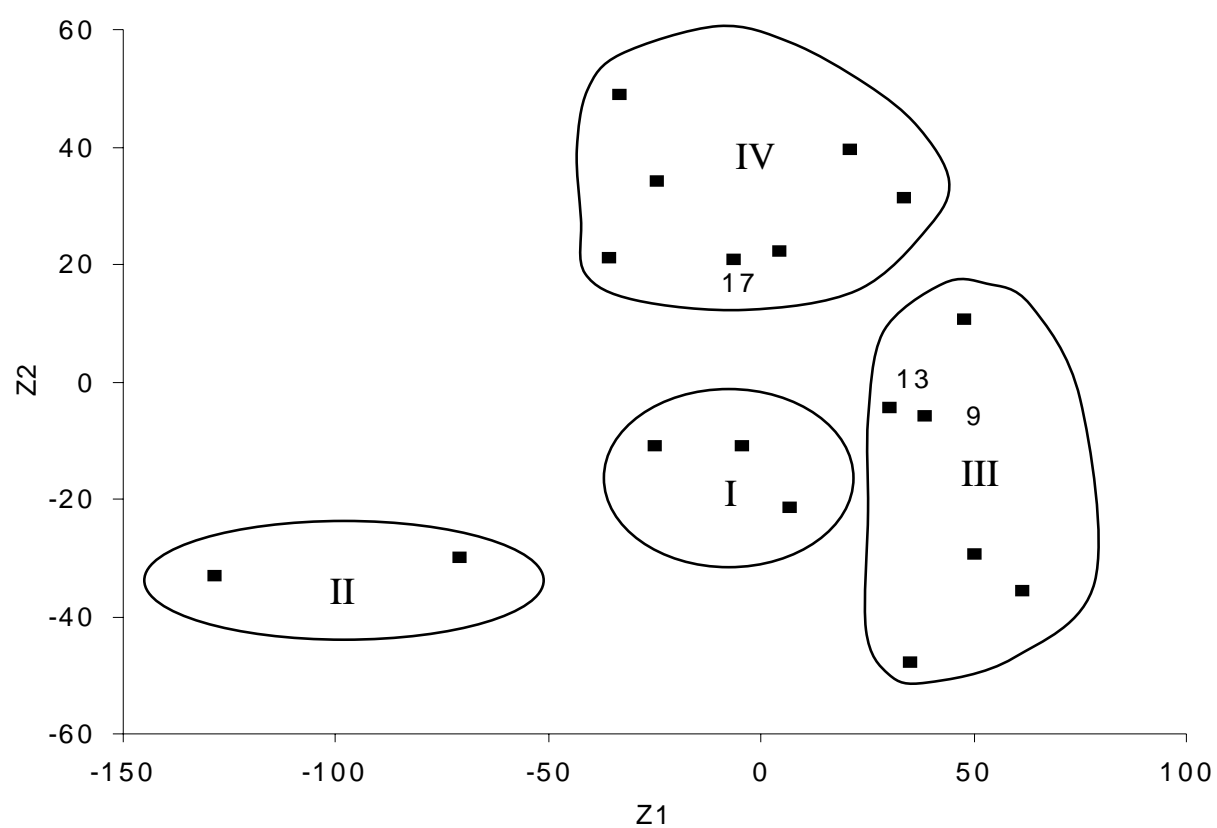

Fig. 2. Scatter distribution of 18 Brassica rapa genotypes based on their principal component scores superimposed with clustering. 
After comparing $\mathrm{D}^{2}$ values, 18 genotypes were grouped into four clusters. Cluster IV had maximum number of (7) genotypes followed by III, I and II which had 6, 3, and 2 genotypes, respectively (Table 3). These results confirmed the clustering pattern of the genotypes obtained through principal component analysis. Golakiya and Makne (1991) while assessing genetic diversity of 23 genotypes and grouped them into six clusters. Reddy et al. (1987) reported on 48 genotypes grouped into 11 clusters. On the other hand, Baydar and Bayraktar (1994) reported 35 genotypes divided into 6 clusters. Badignnavar et al. (2002), Joel and Mylsamy (1998), Islam and Islam (2000) found the same results from compositions of different clusters with their corresponding genotypes in each cluster. The clustering pattern of the genotypes under this study revealed that the genotypes collected from the same location can also group into different clusters. The genotypes belonging to different locations were grouped in the same cluster (Table 3). This shows that geographic diversity was not related to genetic diversity of these materials.

Table 3. Distribution of $\mathbf{1 8}$ genotypes of Brassica rapa in four clusters.

\begin{tabular}{c|c|l}
\hline Clusters & Number of genotypes & \multicolumn{1}{c}{ Name of genotypes } \\
\hline I & 3 & G2, G8, G14 \\
II & 2 & G5, G18 \\
III & 6 & G1, G3, G9, G10, G12, G13 \\
IV & 7 & G4, G6, G7, G11, G15, G16, G17 \\
\hline
\end{tabular}

The inter-cluster distances were higher than the intra-cluster distances suggesting wider genetic diversity among the genotypes of different groups. Singh et al. (1987) obtained larger inter-cluster distances than the intra-cluster distances in a multivariate analysis in mustard.

Table 4. Average inter cluster distance $\left(\mathrm{D}^{2}\right)$ and Intra cluster distance (bold) for 18 Brassica rapa genotypes.

\begin{tabular}{c|c|c|c|c}
\hline Cluster & I & II & III & IV \\
\hline I & $\mathbf{0 . 6 3 0}$ & & & \\
II & 8.721 & $\mathbf{1 . 0 5 7}$ & & \\
III & 3.619 & 11.697 & $\mathbf{0 . 6 3 1}$ & \\
IV & 3.941 & 9.812 & 6.770 & $\mathbf{0 . 7 3 9}$ \\
\hline
\end{tabular}

The highest inter-cluster distance was observed between clusters II and III (11.697), followed by between cluster II and IV (9.812), I and II (8.721), III and IV (6.770) (Table 4). The lowest inter-cluster distance was observed between cluster I and III (3.619), followed by I and IV (3.941). The maximum inter-cluster distance was observed between the clusters II and III (11.697) maintaining more distance than other clusters. Genotypes from 
these two clusters if involved in hybridization may produce a wide spectrum of segregating population. Similar reports were also made by Singh et al. (1991) reported that the greater genetic distances implying higher heterosis than those with similar genetic distances.

Table 5. Cluster means for 10 characters of 18 Brassica rapa genotypes.

\begin{tabular}{lcccc}
\hline Characters & I & II & III & IV \\
\hline Plant height & 105.64 & 94.75 & 109.63 & 94.91 \\
No. of primary branches/plant & 5.99 & 4.40 & 5.97 & 5.56 \\
No. of secondary branches/plant & 5.84 & 3.17 & 7.51 & 6.49 \\
Days to 50\% flowering & 35.56 & 37.83 & 33.56 & 32.33 \\
Days to maturity & 95.33 & 90.83 & 91.67 & 92.81 \\
Siliquae/plant & 186.86 & 106.43 & 236.72 & 174.83 \\
Siliqua length & 3.86 & 4.53 & 3.70 & 3.84 \\
Seeds/pod & 17.18 & 18.22 & 15.71 & 17.22 \\
1000-seed wt. & 2.89 & 3.00 & 2.89 & 2.87 \\
Yield/plant & 6.26 & 4.78 & 7.16 & 6.43 \\
\hline
\end{tabular}

Cluster means for ten characters are presented in Table 5. Primary branches per plant had the highest mean (5.99) in cluster 1. Days to flowering, siliqua length, seeds per pod, and 1000-seed weight had the highest means (37.83, 4.53, 18.22 and 3.00, respectively), while primary branches per plant and secondary branches per plant had the lowest means (4.40 and 3.17, respectively). Plant height, secondary branches per plant, siliquae per plant and yield per plant had the highest means (109.63, 7.51, 236.72, and 7.16, respectively), while siliqua length and seeds per pod had the lowest means (3.70 and 15.71, respectively). Considering duration and yield, crosses involving cluster II and cluster III may exhibit high heterosis for yield. Crosses between the genotypes belonging cluster II with cluster IV and genotypes in cluster I with cluster II might produce high heterosis for yield as well as for earliness. Also the crosses between genotypes from cluster II with cluster I and IV might produce high level of segregating population. So the genotypes belonging to cluster I and cluster II, cluster II and cluster IV and cluster III and cluster IV have been selected for future hybridization program.

Contribution of characters towards divergence of the genotypes is presented in Table 6. The vector-I $\left(Z_{1}\right)$ obtained from PCA, the important characters responsible for genetic divergence in the first axis of the differentiation were 1000 -seed wt (3.2986), no. of primary branches/plant (1.2725), no. of secondary branches/plant (0.2329) and days to 50\% flowering (0.0216). In vector-II $\left(\mathrm{Z}_{2}\right)$, no. of primary branches/plant (0.4983), seeds/pod (0.4577), days to $50 \%$ 
flowering (0.2696), days to maturity (0.0868), siliquae/plant (0.0013) and no. secondary branches/plant (0.0004) were important, but plant height, days to maturity, siliquae/plant, siliqua length, seeds/pod, yield/plant played only a minor role in the first axis of differentiation. The role of number of primary branches/plant, number of secondary branches/plant and days to $50 \%$ flowering in both the vectors were important components for genetic divergence in these materials

Table 6. Latent Vectors for 10 characters of 18 Brassica rapa genotypes.

\begin{tabular}{lcc}
\hline Characters & Vectors 1 & Vectors 2 \\
\hline Plant height & -0.0410 & -0.1276 \\
No.of primary branches/plant & 1.2725 & 0.4983 \\
No.of secondary branches/plant & 0.2329 & 0.0004 \\
Days to 50\% flowering & 0.0216 & 0.2696 \\
Days to maturity & -0.3396 & 0.0868 \\
Siliquae/plant & -0.0893 & 0.0013 \\
Siliqua length & -0.1884 & -1.9633 \\
seed/pod & -0.2035 & 0.4577 \\
1000-seed wt & 3.2986 & -0.0089 \\
Yield/plant & -0.6378 & -0.6309 \\
\hline
\end{tabular}

Considering the magnitude of genetic distance, contribution of character towards divergence, magnitude of cluster mean and agronomic performance the genotypes G2 for higher seed yield/plant and for highest 1000-seed wt, G8 for lower plant height, lower days to $50 \%$ flowering and G14 for lower days to maturity from cluster I; G18 for highest length of siliqua and lower days to maturity from cluster II; G1 for highest number of primary branches/plant and for highest yield/plant; G3 for higher number of siliquae/plant and G9 for lower days to 50\% flowering, G12 for highest number siliqua/plant from cluster III; G16 for lowest days to maturity and G17 for lowest days to 50\% flowering and plant height from cluster IV were found promising. Therefore, considering group distance and other agronomic performance, genotypes G2 and G14 from cluster I; G18 from cluster II; G1, G9 and G12 from cluster III and G16 and G17 from cluster IV may be considered as better parents for future uses in hybridization program.

\section{References}

Abraham, V. 1994. Rate of out-crossing in Indian mustard, Brassica juncea. Cruciferae Newsletter 16: 69-70.

Anand, I. J. and D. S. Rawat. 1984. Genetic diversity, combining ability and heterosis in brown mustard. Indian J. Genet. Pl. Breed. 44(2): 226-234. 
Ashana, A. N. and V. K. Pandey. 1980. Genetic divergence in linseed. Indian J. Genet. Pl. Breed. 40: 247-250.

Badignnavar, A. K., D. M. Kale and G. S. S. Murty. 2002. Genetic variability and diversity in groundnut genotypes. Plant Breeding. 121(4): 348-353.

Baydar, H. and N. Bayraktar. 1994. Correlation and path coefficient analysis among quantitative characters on Virginia type peanut (Arachis hypogaea L.) cultivars. Ankara Universities Ziraat Fakiiltesi Yilligi. 44(1/2): 59-64.

BBS. 2008. Monthly Statistical Bulletin of the Bangladesh Bureau of Statistics (August). Administration and MIS Wing, Bangladesh Secretariat, Dhaka. www.bbs.gov.bd.

De, R. N., R. Seethara, M. K. Sinha and S. P. Banarjee. 1988. Genetic divergence in rice. Indian J. Genet Pl. Breed. 48: 189-194.

Golakiya, P. R. and V. G. Makne 1991. Genetic diversity in Spanish bunch groundnut. J. Maharastra Agric. Univ. 16(3): 337-339.

Islam, M. S. and M. O. Islam. 2000. Genetic diversity in rapeseed and mustard (Brassica sp.). Bangladesh J. Pl. Breed. Genet. 13(2): 25-30.

Joel, A. J. and V. Mylsamy. 1998. Genetic divergence in groundnut. Madras Agril. J. 85(2): 134-135.

Mahalanobis, P.C. 1936. On the generalized distance in statistics. Proc. Natl. Sc. India.2: 49-55.

Rakow, G. and D. L. Woods. 1987. Outcrossing in rape and mustard under Saskatchewan prairies conditions. Can. J. Plant Sci. 67: 147-151.

Rao. C.R. 1952. Advanced statistical method in biometrical research. Jhon wily and Son. New York.

Reddy, V. R. G., B. N. Singh and B. Rai. 1987. Analysis of genetic divergence in spreading varieties of groundnut. Crop Impro. 14(2): 149-152.

Singh, P. 1983. Studies on genetic variability and diversity of rice. Madras Agric. J. 70(7): 436-440.

Singh, P., M. K. Khera and V. P. Gupta. 1991. Variability and correlation studies for oil and seed yield in gobhi sarson. Crop Improvement 18(2): 99-102.

Singh R. P., D. P. Singh and B. D. Chaudhury. 1987. Morphological variation in Indian mustard. Annal. Biol. 3(1): 26-31. 